\title{
Antioxidant activity and HPTLC profile of Lagenaria siceraria fruits
}

\author{
P. ERASTO* and Z.H. MBWAMBO \\ Department of Natural Products Development and Formulations, Institute of Traditional Medicine, Muhimbili \\ University of Health and Allied Sciences, PO Box 65001, Dar es Salaam, Tanzania
}

\begin{abstract}
The fruits of Lagenaria siceraria Standl. (Cucurbitaceae) are widely used for medicinal and nutritional purposes in Africa. The health promoting ability of the fruits might be related to antioxidant properties of its constituents. In this study the antioxidant effect of fresh and dried fruits of L. siceraria was evaluated by comparing the 2,2-diphenyl-1,1-picrylhydrazyl (DPPH) radical scavenging and reducing capacity of ethyl acetate and n-butanol extracts of fresh and dried fruits. The comparison was further emphasized by high performance thin layer chromatography (HPTLC) analysis of the extracts so as to relate activities with their chemical profiles. Results indicated that ethyl acetate (EA) extract of the fresh fruits exhibited higher DPPH radical scavenging activity than other samples. At $0.01 \mathrm{mg} / \mathrm{ml}$ the order of activity was: EA dried fruits $(50.6 \%)$ $<\mathrm{Bt}(n$-butanol) fresh fruits $(53.3 \%)<\mathrm{Bt}(n$-butanol) dried fruits $(64.8 \%)<$ EA fresh fruits $(68.6 \%)<$ Gallic acid $(81.8 \%)$. A slight change of activity was observed at $0.1 \mathrm{mg} / \mathrm{ml}$, where the order was; EA dried fruits $(70 \%)<$ Bt dried fruits $(71.8 \%) \leq$ Bt fresh fruits $(72 \%)<$ EA fresh fruits $(81.6 \%)<$ Gallic acid $(88.5 \%)$. In the reducing capacity assay, Bt fresh fruits extract exhibited higher reducing power than all test samples. The HPTLC chemical profiles of both fresh and dried fruit extracts showed some slight differences. The slight differences in antioxidant activities were justified by the HPTLC chemical profiles of the fruits. Therefore, taking fresh or dried fruits of $L$. siceraria may relatively give similar antioxidant effects. Since the fruits of this plant matures in bulky, then drying, milling and packing the products under hygiene environment can ensure a constant supply of antioxidant supplement.
\end{abstract}

Keywords: Antioxidant, free radical scavenging, HPTLC profile, Lagenaria siceraria

\section{Introduction}

The generation of reactive oxygen species (ROS) and free radicals in human is suggested to contribute to the wide range of pathological disturbances such as, inflammations, cancer, diabetes and arthritis (Shindo et al., 2004; Erasto et al., 2007). The free radicals are generated from cellular and metabolic activities, and also through exogenous sources such as human exposure to ionizing radiation, injury, oxidative drugs and pollutants (Hsu et al., 2006). Although free radicals and ROS are important, the human body constantly quenches excessive oxidants through various scavenging mechanisms such as use of antioxidant enzymes and molecules.

Natural products derived from food and medicinal plants are the potential sources of antioxidant molecules (Jodynis-Liebert et al., 2000; Erasto et al., 2007). Lagenaria siceraria Standl. (Cucurbitaceae) is an important food and medicinal plant species found throughout sub-Saharan Africa (Smith \& Eyzaguirre, 2007). In Tanzania, the fruits of this plant species are used for medicinal and culinary purposes. Medicinally, fruits are also used in the treatment of diabetes (unpublished data). Other uses include the treatment of cough, asthma, jaundice, kidney stone, colds and measles (Jain \& Sharma, 1967; Han et al., 1984; Okoli, 1984; Al-khalil, 1995). Furthermore, the fruits have laxative and diuretic properties (Al-khalil, 1995).

The pharmacological properties of $L$. siceraria fruits have narrowly been investigated. This includes screening for cytotoxicity, anticancer and antihepatotoxicity properties (Answal et al., 1984; Furukawa et al., 1995; Shiwaikar \& Sreenivasan, 1996). Despite the fact that fruits of L. siceraria are used as food and for medicinal purposes, there is no information on antioxidant properties. It has been suggested that the aetiology of complications of some physiological ailments such as diabetes involves oxidative stress, perhaps as a result of hypoglycaemia (Hunt et al., 1990; Govindarajan et al., 2005). The objective of this study was to assess the antioxidative activity of the fruits of L. siceraria as one of the possible mechanisms of arresting oxidative stress in diabetic people who use this plant as part of their ethnomedical treatment regime. The effect of drying on the chemical profile and antioxidant properties of the fruits was also investigated. Therefore, this paper presents the antioxidant properties and HPTLC profile of various extracts of fresh and dried fruits of L. siceraria.

\footnotetext{
* Correspondence: Dr. Paul Erasto; E-mail: paulkazyoba@yahoo.co.uk
} 


\section{Materials and Methods}

\section{Chemicals}

Gallic acid, 2,2-diphenyl-1-picrylhydrazyl $(\mathrm{DPPH})$, Potassium ferricyanide $\left[\mathrm{K}_{3} \mathrm{Fe}(\mathrm{CN})_{6}\right]$, Trichloroacetic acid $\left(\mathrm{Cl}_{3} \mathrm{CCO}_{2} \mathrm{H}\right)$ and Ferric chloride $\left(\mathrm{FeCl}_{3}\right)$ were purchased from Sigma Aldrich (South Africa). Precoated silica gel glass plate $60 \mathrm{~F}-254(20 \mathrm{~cm} \times 10 \mathrm{~cm}$ with 250 $\mu \mathrm{m}$ thickness) was purchased from E. Merck, Darmstadt, Germany. All solvents were supplied by Unilab Kenya Limited, Nairobi.

\section{Collection of plant materials}

Fresh fruits of Lagenaria siceraria were collected in May 2008 from a cultivated garden in Geita, Mwanza, Tanzania. The plant was identified and the voucher specimen HOS 128 was deposited in the herbarium at the institute of Traditional Medicine, Muhimbili University of Health and Allied Sciences, Tanzania.

\section{Preparation and extraction of plant materials}

A portion of fresh fruits were chopped into small pieces before being ground using a blender (Waring blender, USA). The macerates were shaken in $100 \% \mathrm{MeOH}$ for 18 hours, then filtered and concentrated under vacuo at $50^{\circ} \mathrm{C}$ using a rotary evaporator. Since the fruits were fresh and succulent, the extracts did not dry completely. Therefore, the remaining aqueous solution was partitioned with ethyl acetate and later with n-butanol, to give $5.9 \mathrm{~g}$ of ethyl acetate (EA fresh fruit) and $17.8 \mathrm{~g}$ of $\mathrm{n}$-butanol (Bt fresh fruit) extracts respectively. The extracts were kept in the refrigerator for further use.

The remaining portion of the fresh fruits were chopped into small pieces and dried at ambient temperature. The dried pieces of fruits were milled using an electric miller to give $327 \mathrm{~g}$ of fine powder. The powder was soaked in $100 \% \mathrm{MeOH}$ for 18 hours before being filtered and concentrated under vacuo at $50^{\circ} \mathrm{C}$ to afford $28.5 \mathrm{~g}$ of a dirty brown extract. The whole extract was dissolved in $400 \mathrm{ml}$ of distilled water and subjected to liquid-liquid partition with ethyl acetate and n-butanol, respectively. The extracts were concentrated to dryness under vacuo at $50^{\circ} \mathrm{C}$ to give $4.7 \mathrm{~g}$ of ethyl acetate (EA dried fruits) and $13.4 \mathrm{~g}$ of $\mathrm{n}$-butanol (Bt dried fruits). The extracts were kept in the fridge for further use.

\section{Determination of DPPH radical scavenging activity}

The DPPH radical scavenging activity of various extracts of fresh and dried fruits of Lagenaria siceraria was assessed as described by LiyanaPathirana \& Shahidi (2005). An amount of $0.5 \mathrm{ml}$ of $0.12 \mathrm{mM} \mathrm{DPPH}$ solution in methanol was separately mixed with $2 \mathrm{ml}$ of $0.01,0.025,0.05$ and $0.075 \mathrm{mg} / \mathrm{ml}$ of the extracts in methanol and vortexed thoroughly. The absorbance of the mixture at ambient temperature was recorded for $60 \mathrm{~min}$. at $10 \mathrm{~min}$. intervals. Gallic acid was used as a reference antioxidant compound. The absorbance of the remaining DPPH radicals was read at 519nm using a Jenway $6505 \mathrm{UV} / \mathrm{Vis}$ spectrophotometer (Essex, UK). The analysis of each assay solution was replicated thrice. The scavenging of DPPH radical was calculated according to the following equation:

DPPH radical scavenging activity $(\%)=\left[\left(\mathrm{A}_{\text {control }}-\mathrm{A}_{\text {sample }}\right) /\left(\mathrm{A}_{\text {control }}\right)\right] \times 100$

Where $\mathrm{A}_{\text {control }}$ is the absorbance of DPPH radical in methanol, $\mathrm{A}_{\text {sample }}$ is the absorbance of DPPH radical + sample extract/standard.

\section{Reducing capacity}

Adopting the method of Oyaizu (1986), 0.01, $0.025,0.05$ and $0.075 \mathrm{mg} / \mathrm{ml}$ of fresh and dried fruit extracts were mixed with $2.5 \mathrm{ml}$ of $0.02 \mathrm{M}$ phosphate buffer $(\mathrm{pH} 6.6)$ and $2.5 \mathrm{ml}$ of $1 \%$ potassium ferricyanide $\left[\mathrm{K}_{3} \mathrm{Fe}(\mathrm{CN})_{6}\right]$. The mixture was then incubated at $50^{\circ} \mathrm{C}$ for $20 \mathrm{~min}$. Aliquots $(2.5 \mathrm{ml})$ of $10 \%$ trichloroacetic acid were added to the mixture, which was then centrifuged for $10 \mathrm{~min}$ at $1000 \mathrm{x}$ g. The upper layer of the solution $(2.5 \mathrm{ml})$ was mixed with $2.5 \mathrm{ml}$ of distilled water and $0.5 \mathrm{ml}$ of $0.1 \% \mathrm{FeCl}_{3^{\prime}}$ and the absorbance was measured at 700nm in a Jenway $6505 \mathrm{UV} /$ Vis spectrophotometer. Gallic acid was used as a standard antioxidant compound. The analysis of each assay solution was replicated three-times.

\section{High Performance Thin Layer Chromatography (HPTLC) analysis of the extracts}

The samples were spotted in the form of bands of width $5 \mathrm{~mm}$ with a Camag microlitre syringe on precoated silica gel glass plate 60F-254 $(20 \mathrm{~cm} \times 10 \mathrm{~cm}$ with $250 \mu \mathrm{m}$ thickness (E. Merck, Darmstadt, Germany) using a Camag Linomat IV (Switzerland). The plates were pre-washed by methanol and activated at $60^{\circ} \mathrm{C}$ for $5 \mathrm{~min}$ prior to chromatography. A constant application rate of $0.1 \mu \mathrm{l} / \mathrm{s}$ was employed and space between two bands was $6 \mathrm{~mm}$. The slit dimension was kept at $5 \mathrm{~mm} \times 0.45 \mathrm{~mm}$ and $10 \mathrm{~mm} / \mathrm{s}$ scanning speed was employed. The monochromatic bandwidth was set at $20 \mathrm{~nm}$, each track was scanned thrice 
and baseline correction was used. The mobile phase consisted of dichloromethane-methanol $(10: 1, \mathrm{v} / \mathrm{v})$ for EA dried and fresh fruits extracts and dichloromethane-methanol $(9: 2, \mathrm{v} / \mathrm{v})$ for $\mathrm{Bt}$ fresh and dried fruits extracts. $15 \mathrm{ml}$ of mobile phase was used in each chromatographic development of plates. Linear ascending development was carried out in $20 \mathrm{~cm} \times 10 \mathrm{~cm}$ twin trough glass chamber (Camag, Mutenz, Switzerland) saturated with the mobile phase and the chromatoplate development for two times with the same mobile phase to get good resolution of phytochemical contents. The optimized chamber saturation time for mobile phase was $30 \mathrm{~min}$ at room temperature $\left(25^{\circ} \mathrm{C} \pm 2\right)$. The length of chromatogram run was $8 \mathrm{~cm}$. Subsequent to the scanning, thin layer chromatographic (TLC) plates were dried in a current of air with the help of an air dryer. Densitometric scanning was performed on Camag TLC scanner III in the reflectanceabsorbance mode at $250 \mathrm{~nm}$ and operated by CATS software (V 3.15, Camag). The source of radiation utilized was deuterium lamp emitting a continuous UV spectrum between 190 and 400nm.

\section{Data analysis}

With exception of HPTLC curves of various extracts (chromatograms), all data from antioxidant assays were analyzed using Microsoft Office Excel 2007 programme.

\section{Results}

\section{DPPH radical scavenging}

All samples showed appreciably high DPPH radical scavenging effect at all concentrations. However the ethyl acetate extract from fresh fruits (EA fresh fruits) was more active than the rest samples. At $0.01 \mathrm{mg} / \mathrm{ml}$ the order of activity was; EA dried fruits $<$ Bt fresh fruits $<$ Bt dried fruits $<$ EA fresh fruits $<$ Gallic acid. Whereas at $0.1 \mathrm{mg} / \mathrm{ml}$ the trend was: EA dried fruits $\leq$ Bt dried fruits $\leq$ Bt fresh fruits $<$ EA fresh fruits $<$ Gallic acid. The percentages of radical scavenging effect of both fresh and dried fruit extracts were within close range. This suggests that using extracts from either fresh or dried fruits would relatively give the same effect. Furthermore, the results show that antioxidant molecules are found in both medium polar and polar extracts of the L. siceraria fruits.

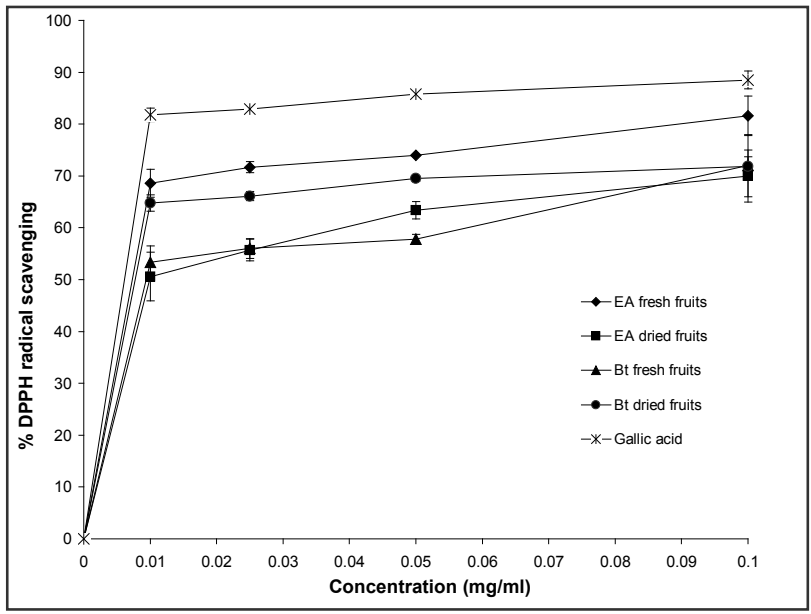

Figure 1: The DPPH radical scavenging activity ethyl acetate (EA) and n-butanol (Bt) extracts of fresh and dried fruits of L. siceraria compared with Gallic acid after $60 \mathrm{~min}$ of reaction. Each value is expressed as mean $\pm \operatorname{SD}(n=3)$

\section{Reducing capacity}

The antioxidant activity of the extracts from fresh and dried fruits of L. siceraria was further manifested through their reducing capacity as shown in Figure 2. In this assay the $\mathrm{Fe}^{3+} \rightarrow \mathrm{Fe}^{2+}$ transformation was established as reducing capacity. The Bt fresh fruits extract exhibited higher activity than other samples at all concentrations. At the lowest concentration of $0.01 \mathrm{mg} / \mathrm{ml}$, the order of activity was: Bt dried fruits $<$ Gallic acid $<$ EA fresh fruits $<$ EA dried fruits $<$ Bt fresh fruits, whereas at $0.1 \mathrm{mg} / \mathrm{ml}$ the activity order was; Bt dried fruits $<$ Gallic acid $<$ EA dried fruits $\leq$ EA fresh fruits $<$ Bt fresh fruits. Although the difference in activities of extracts is marginal, it still shows that fresh fruits have more reducing power than the dried ones. This assay confirmed further that medium polar and high polar extracts of fresh and dried fruits of this species possess antioxidant properties.

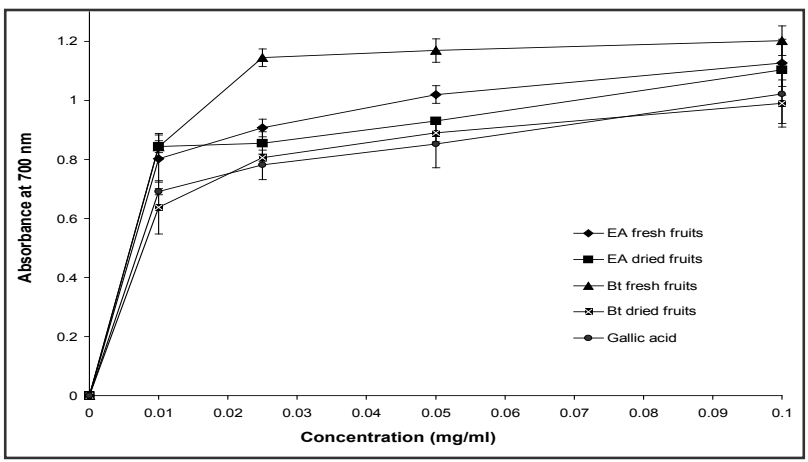

Figure 2: Reducing capacity of different amounts of ethyl acetate (EA) and n-butanol (Bt) extracts of fresh and dried fruits of $L$. siceraria compared to Gallic acid (a standard antioxidant compound) using spectrophotometric detection of the $\mathrm{Fe}^{3+} \rightarrow$ $\mathrm{Fe}^{2+}$ transformation. Each value is expressed as mean $\pm \operatorname{SD}(n=3)$. 


\section{HPTLC profiles of the extracts}

The extracts of fresh and dried fruits of $L$. siceraria were subjected to HPTLC analysis. This was done with the aim of studying the effect of drying the fruits on the chemical profiles and antioxidant activities of extracts. The ethyl acetate extracts of dried (EA dried fruits) and fresh fruits (EA fresh fruits) showed some variation in the number of compounds. The EA dried fruits had more compounds than the EA extract of fresh fruits (Figure 3 and 4).

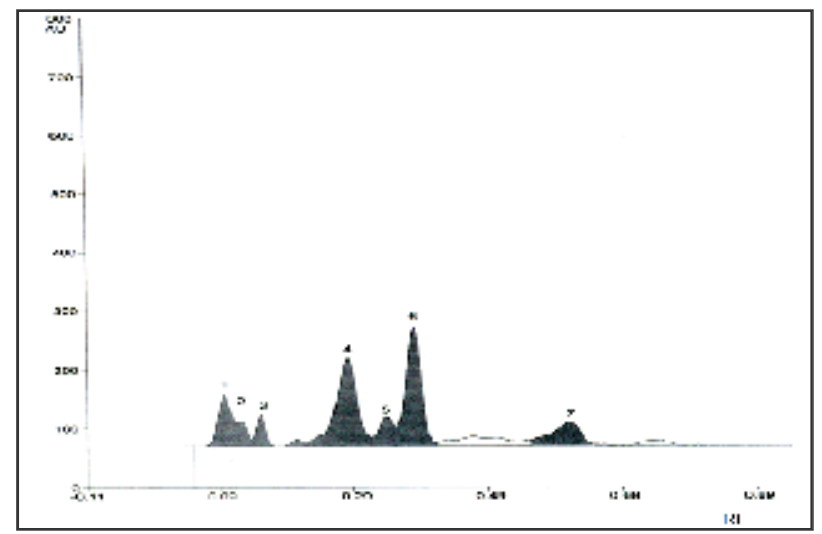

Figure 3: HPTLC profile of ethyl acetate extract of fresh fruits (EA fresh fruits) of L. siceraria as developed in dichloromethane/methanol (10:1, v/v) mobile phase.

The EA fresh fruits extract had seven peaks whereas EA dried fruits extract had nine major peaks. Some likely common compounds in each case were: peaks 1, 4, 5 and 7 with Rf values of 0.1 , $0.29,0.35$ and 0.64 for EA fresh fruits and peaks 1, $3,4,8$ with Rf values of $0.13,0.27,0.33$ and 0.61 for EA dried fruits (Figure 3 and 4 ) respectively.

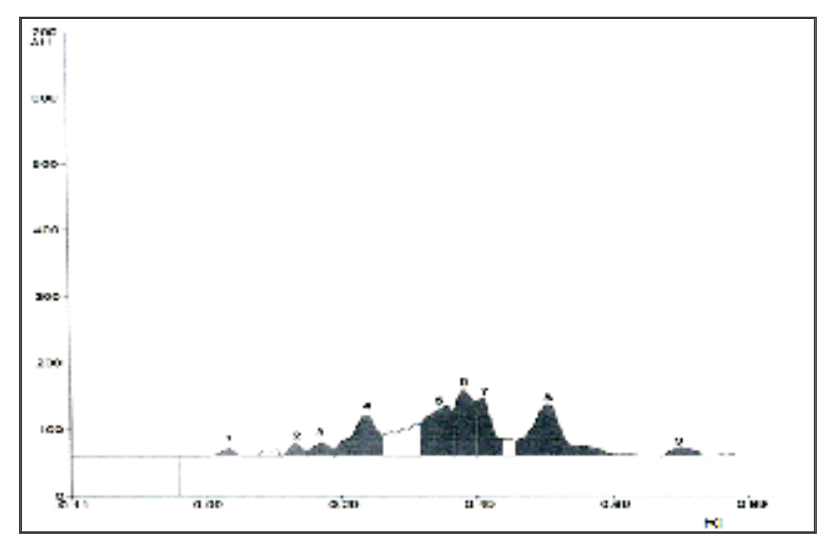

Figure 4: HPTLC profile of ethyl acetate extract of dried fruits (EA dried fruits) of $L$. siceraria as developed in dichloromethane/methanol (10:1, v/v) mobile phase

The n-butanol (Bt) extracts of fresh and dried fruits showed some little differences in their chemical component in which the former had four peaks while the latter had three (Figure 5 and 6).

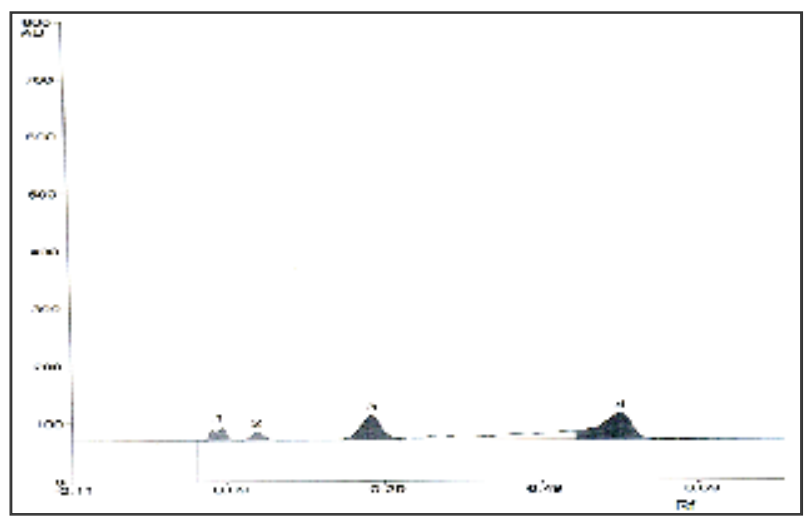

Figure 5: HPTLC profile of $n$-butanol extract (Bt fresh fruits) of fresh fruits of $L$. siceraria as developed in dichloromethane/methanol (9:2, v/v) mobile phase.

The common compounds in each sample were; peaks 2, 3 and 4 with Rf values of $0.13,0.28$ and 0.6 for Bt fresh fruits and peaks 1, 2 and 3 with Rf values of $0.14,0.27$ and 0.61 for Bt dried fruits respectively. The results suggest that drying the fruits of L. siceraria does not cause significant change of chemical profile of extracts.

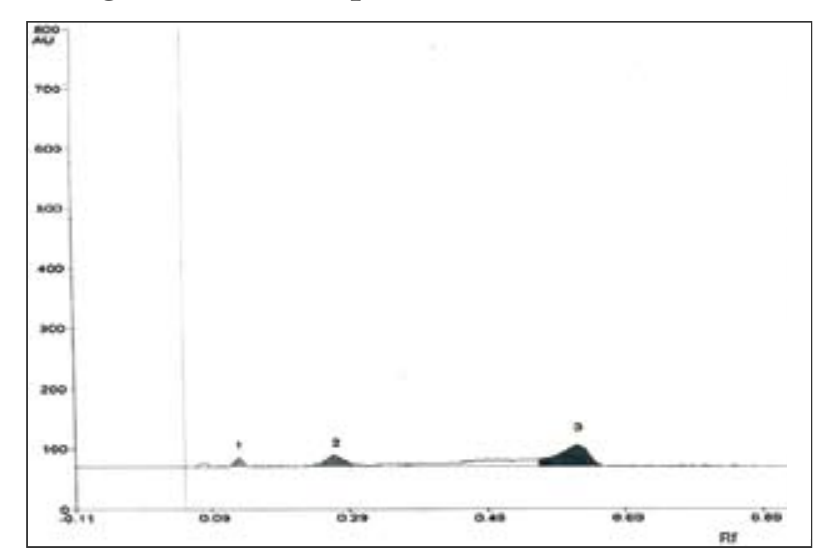

Figure 6: HPTLC profile of $n$-butanol extract of dried fruits (Bt dried fruits) of $L$. siceraria as developed in dichloromethane/methanol (9:2, v/v) mobile phase.

\section{Discussion}

The extracts of fresh and dried fruits of Lagenaria siceraria exhibited appreciably high antioxidant activity as manifested through DPPH radical scavenging and reducing capacity assays. Comparing the activities of the two sets of extracts, ethyl acetate (EA) and n-butanol (Bt) fresh fruits extracts had superior activity than their corresponding extracts from dried fruits. The observed slight variation of antioxidant activities of extracts was further justified by their HPTLC chemical profiles. It revealed that the number of compounds in fresh and dried fruit extracts varied slightly, and that could be 
responsible for the observed slight disparities in their antioxidant activities.

This study has established that, there are minor differences in antioxidant properties and chemical profiles between fresh and dried fruit extracts. Therefore, taking fresh or dried fruits may relatively give similar antioxidant effects. The fruits of $L$. siceraria mature in bulk quantities, since they are needed for food and medicinal purposes, drying, milling and packing the product under hygienic environment can ensure a constant supply of antioxidant supplement. Therefore diabetic patients may avert oxidative stress through consumption of fruits of this species or use of extracts derived thereof. However, further study on the in vivo antioxidant effects of the fruit extracts of $L$. siceraria is needed before standardization and formulation of the powdered product can be achieved.

\section{Acknowledgements}

The authors thank the Pacific Way Foundation (Vancouver, Canada) for financial support. Mr. Haji O. Selemani of the Department of Botany of the University of Dar es Salaam is thanked for identifying the plant species. Mr. Danstan Shewiyo of Tanzania Food and Drug Authority is appreciated for the technical support during HPTLC analysis of samples.

Received 21 March 2009

Revised 24 March 2009

Accepted 25 March 2009

\section{References}

Al-khalil, S. (1995) A survey of plants used in Jordanian traditional medicine. International Journal of Pharmacognosy 33, 317-323.

Answal, B.S., Bhakuni, D.S., Goel, A.K., Kar, K., Mehrotra, B.N. \& Mukherjee, K.C. (1984) Screening of Indian plants for biological activity: Part X. Indian Journal Experimental Biology 22, 312-332.

Erasto, P., Grierson, D.S. \& Afolayan, A.J. (2007) Antioxidant constituents in Vernonia amygdalina leaves. Pharmaceutical Biology 45, 195-199.

Furukawa, K., Yamamoto, I., Tanida, N., Tsujiai, T., Nishikawa, M., Nariswa, T. \& Shimoyama, T. (1995) The effects of dietary fiber from Lagenaria siceraria (Yugao melon) on colonic carcinogenesis in Mice. Cancer 75, 1508-1515.

Govindarajan, R., Vijayakumar, M. \& Pushpangadan, P. (2005) Antioxidant approach to disease management and the role of 'Rasayana' herbs of Ayurveda. Journal of Ethnopharmacology 99, 165 $-178$.

Han, D.S., Lee, S.J. \& Lee, H.K. (1984) Ethnobotanical survey in Korea. Proceedings of the fifth Asian Symposium on Medicinal Plants and Spices, Seoul Korea. August 20-24 1984. BH, Han, DS Han, YN Han and WS Wool (Eds), 125-144.

Hsu, H., Coupar, I.M. \& Ng, K. (2006) Antioxidant activity of hot water extract from the fruit of the Doum palm, Hyphaene thebaica. Food Chemistry 98, 317-328.

Hunt, J.V., Smith, C.C.T. \& Wolff, S.P. (1990) Auto-oxidative glycosylation and possible involvement of peroxides and free radicals in LDL modification by glucose. Diabetes 39, 1420-1424.

Jain, S.R. \& Sharma, S.N. (1967) Hypoglycaemic drugs of Indian indigenous origin. Planta Medica 15, 439-442.

Jodynis-Liebert, J., Murias, M. \& Bloszyk, E. (2000) Effect of sesquiterpene lactones on antioxidant enzymes and some drugmetabolizing enzymes in rat liver and kidney. Planta Medica 66, 199-205.

Liyana-Pathirana, C.M. \& Shahidi, F. (2005) Antioxidant activity of commercial soft and hard wheat (Triticum aestivum L.) as affected by gastric $\mathrm{pH}$ conditions. Journal of Agriculture and Food Chemistry 53, 2433-2440.

Okoli, B.E. (1984) Wild and cultivated Cucurbits in Nigeria. Economic Botany 38, 350-357.

Oyaizu,M.(1986)Studies on productofbrowning reaction prepared from glucose amine. Japanese Journal of Nutrition 44, 307-315.

Shindo, K., Kimura, M. \& Iga, M. (2004) Potent antioxidative activity of cacalol, a sesquiterpene contained in Cacalia delphiniifolia Sleb et Zucc. Bioscience Biotechnology and Biochemistry 68, 13931394.

Shiwaikar,A.\&Sreenivasan,K.K.(1996)Chemical investigation and antihepatotoxicity activity of the fruits of Lagenaria siceraria. Indian Journal of Pharmaceutical Science 58, 197-202.

Smith, F.I. \& Eyzaguirre, P. (2007) African leafy vegetables: their role in the World Health Organization's Global fruit and vegetable initiative. African Journal of Food Agriculture Nutrition and Development 7, 3. 